\title{
A study of inducible clindamycin resistance in erythromycin resistant clinical isolates of staphylococcus species
}

\author{
Fatima Khan, Sana Ali, Asfia Sultan, Meher Rizvi, Abida Khatoon, Indu Shukla, Haris M Khan \\ Department of Microbiology, Jawaharlal Nehru Medical College and Hospital, AMU, Aligarh, U.P. INDIA
}

\section{A B S T R A C T}

Introduction: Erythromycin resistant Staphylococcus isolates with inducible resistance appear sensitive to clindamycin in in-vitro sensitivity testing. If clindamycin is used for treatment of such isolates, selection for constitutive mutants may lead to clinical failure. Current study was conducted to detect the presence of inducible clindamycin resistance in erythromycin resistant Staphylococcus isolates by disk diffusion method (D test). To correlate clindamycin resistance phenotypes with minimum inhibitory concentrations (MICs) of clindamycin, erythromycin, oxacillin and vancomycin among the isolates. To correlate various resistance phenotypes with methicillin resistance. Material and Methods: 150 non duplicate isolates of Staphylococcus species were identified and antibiotic susceptibility testing was done using Kirby Bauer's disc diffusion method. MICs were determined using E-test for oxacillin, vancomycin, clindamycin and erythromycin using E-test strips (Himedia) Results: Among 150 staphylococcus clinical isolates, 96 were of $\mathcal{S}$. aureus and 54 were coagulase negative Staphylococci (CONS). About $81.2 \%$ of the S.aureus isolates and $72.2 \%$ of the CONS were found to be methicillin resistant. Inducible clindamycin resistance was found in $39.3 \%$ of the isolates, constitutive resistance phenotype in $48 \%$ while $12.7 \%$ demonstrated MS phenotype. $18 \%$ and $11.3 \%$ of all the isolates had MICs for clindamycin between $0.01-0.06 \mu \mathrm{g} / \mathrm{ml}$ and $0.06-0.1$ respectively. $12.5 \%$ had MIC ranging from $4-8 \mu \mathrm{g} / \mathrm{ml}$ while $58 \%$ had MIC $>8 \mu \mathrm{g} / \mathrm{ml}$. Constitutive resistant phenotype (cMLS) was the predominant phenotype in methicillin resistant isolates. MS phenotype was the predominant among MSSA (methicillin sensitive S. aureus) while MSCNS (methicillin sensitive CONS) cMLS (46.7\%) predominated. MIC of all erythromycin resistant isolates were $\geq 240 \mu \mathrm{g} / \mathrm{ml}$. Nearly $16.7 \%$ of the cMLS and $57.9 \%$ of MS isolates were found to be oxacillin sensitive and $83 \%$ of iMLS and $83.3 \%$ of MS phenotype isolates were oxacillin resistant on MIC testing. 47.2\% of cMLS and 73.6\% of MS isolates had MIC $\leq 2 \mu \mathrm{g} / \mathrm{ml}$ for vancomycin and $52.7 \%$ of cMLS and $26.3 \%$ of MS isolates had MICs in intermediate range for vancomycin. Conclusions: D-testing might help clinicians to decide whether to use clindamycin in Staphylococcal infections when erythromycin resistance is present. Determination of MICs help to identify exact sensitivity profile of isolates in cases where clinical failure occurs due to misleading disk diffusion tests.

Key words: Staphylococcus, Erythromycin, Clindamycin, MRSA, D-test
Access this article online Website:

http://nepjol.info/index.php/AJMS DOI: 10.3126/ajms.v6i6.11811

\section{INTRODUCTION}

Macrolide-lincosamide-streptogramin (MLS) antibiotics are commonly used in treatment of Staphylococcal infections especially methicillin resistant staphylococci. ${ }^{1}$ Clindamycin (CLI) is a frequent choice for some Staphylococcal infections, especially skin and soft-tissue infections. Macrolide antibiotic resistance in Staphylococcus aureus and coagulase-negative
Staphylococci (CONS) may be due to an active efflux mechanism encoded by msrA (conferring resistance to macrolides and type B streptogramins only ${ }^{2,3}$ or may be due to ribosomal target modification, affecting macrolides, lincosamides, and type B streptogramins (MLSB resistance). erm genes encode enzymes that confer inducible or constitutive resistance to MLS agents via methylation of the $23 \mathrm{~S}$ rRNA, reducing binding by MLS agents to the ribosome. ${ }^{4}$ Rarely resistance could be 
due to inactivation of lincosamides by chemical alteration mediated by inu $A$ gene. ${ }^{4}$

Erythromycin (ERY) is an effective inducer whereas CLI is a weak inducer. ${ }^{5}$ In vitro Staphylococcus aureus isolates with constitutive resistance are resistant to both ERY and CLI whereas those with inducible resistance are resistant to ERY and appear sensitive to CLI (iMLS ${ }_{\mathrm{B}}$. ${ }^{6}$ If clindamycin is used for treatment of such an isolate (iMLS ${ }_{\mathrm{B}}$ ), selection for constitutive erm mutants occurs which may lead to clinical failure. This inducible MLS $_{\mathrm{B}}$ resistance can be detected by a simple disc approximation test, commonly referred to as D-test. For this test, an ERY $(15 \mu \mathrm{g})$ disc is placed $15-26 \mathrm{~mm}$ (edge to edge) from a CLI $(2 \mu \mathrm{g})$ disc in a standard disc diffusion test. Following incubation, a flattening of the zone in the area between the discs where both drugs have diffused indicates that the organism has inducible clindamycin resistance.

Current study was undertaken to study the prevalence of inducible clindamycin resistance in erythromycin resistant Staphylococcus isolates using D- Test. To correlate various clindamycin resistance phenotypes with minimum inhibitory concentrations (MICs) of clindamycin, erythromycin, oxacillin and vancomycin among the isolates and to study these resistance phenotypes in relation to methicillin resistance.

\section{MATERIAL AND METHODS}

The prospective study was conducted in the Department of Microbiology, J.N Medical College. One hundred fifty non duplicate clinical isolates of erythromycin resistant Staphylococcus species isolated from samples received from various outpatient and inpatient departments of the hospital were included in the study. The isolates were identified using standard biochemicals and antibiotic susceptibility testing was done using Kirby Bauer's disc diffusion method on Mueller Hinton agar using erythromycin $(15 \mu \mathrm{g})$, norfloxacin $(5 \mu \mathrm{g})$, vancomycin (30 $\mu \mathrm{g})$, clindamycin $(2 \mu \mathrm{g})$, oxacillin $(1 \mu \mathrm{g})$, and cefoxitin $(30 \mu \mathrm{g})$ as per CLSI guidelines. ${ }^{8}$ Erythromycin and clindamycin disks were placed adjacent to each other at a distance of $15 \mathrm{~mm}$ (edge to edge) to detect inducible resistance. Isolate was labelled as erythromycin resistant if zone size was $\leq 13 \mathrm{~mm}$ and resistant to clindamycin if zone size was $\leq 14$. Sensitive zone size for clindamycin was $\geq 21 \mathrm{~mm}$. Erythromycin resistant isolates were further tested for minimum inhibitory concentrations (MICs) of erythromycin, clindamycin, oxacillin and vancomycin using E-test strips (HiMedia). All the erythromycin-sensitive strains were excluded from the study.
Following phenotypes were observed after disk diffusion testing.

a. Inducible MLS (iMLS) phenotype-Staphylococcal isolates showing resistance to erythromycin while being sensitive to clindamycin and giving D-shaped zone of inhibition around clindamycin with flattening towards erythromycin disc.

b. Constitutive MLS (cMLS) phenotype - Those Staphylococcal isolates, which showed resistance to both erythromycin and clindamycin with circular shape of zone of inhibition, if any around clindamycin.

c. MS phenotype - Isolates exhibiting resistance to erythromycin and sensitivity to clindamycin and giving circular zone of inhibition around clindamycin.

Determination of minimum inhibitory concentration (MIC) using E-test: MICs were determined using E-test for oxacillin, vancomycin, clindamycin and erythromycin in all isolates. Test was done using E-test strips (Himedia) with the following graded concentrations of antibiotics according to manufacturer's instructions.

Oxacillin: Oxacillin Ezy MIC ${ }^{\mathrm{TM}}$ Strip (OXA) $(0.016-256 \mu \mathrm{g} / \mathrm{ml})$. MIC $\leq 2 \mu \mathrm{g} / \mathrm{ml}$ was taken as sensitive and $\geq 4 \mu \mathrm{g} / \mathrm{ml}$ as resistant for Staphylococcus aureus. In CONS, MIC $\leq 0.25 \mu \mathrm{g} / \mathrm{ml}$ was regarded as sensitive and $\geq 0.5 \mu \mathrm{g} / \mathrm{ml}$ as resistant.

Vancomycin: Vancomycin Ezy MIC ${ }^{\mathbf{T M}}$ Strips (VAN) $(0.016-256 \mu \mathrm{g} / \mathrm{ml})$. MIC $\leq 2 \mu \mathrm{g} / \mathrm{ml}$ was taken as sensitive, $4-8 \mu \mathrm{g} / \mathrm{ml}$ as intermediate and $\geq 16 \mu \mathrm{g} / \mathrm{ml}$ as resistant.

Clindamycin: Clindamycin HiComb ${ }^{\mathrm{TM}}$ MIC Strip having antibiotic concentration gradient from $0.001-8 \mu \mathrm{g} / \mathrm{ml}$. MIC $\leq 0.5 \mu \mathrm{g} / \mathrm{ml}$ was taken as sensitive, $1-2 \mu \mathrm{g} / \mathrm{ml}$ as intermediate and $\geq 4 \mu \mathrm{g} / \mathrm{ml}$ as resistant.

Erythromycin: Erythromycin HiComb ${ }^{\mathrm{TM}}$ MIC Strip $(0.01-240 \mu \mathrm{g} / \mathrm{ml}) . \mathrm{MIC} \leq 0.5 \mu \mathrm{g} / \mathrm{ml}$ was taken as sensitive, $1-4 \mu \mathrm{g} / \mathrm{ml}$ as intermediate and $\geq 8 \mu \mathrm{g} / \mathrm{ml}$ as resistant.

\section{RESULTS}

Of the 150 erythromycin resistant staphylococcus isolates, 96 were of Staphylococcus aureus and 54 were coagulase negative Staphylococci (CONS). Seventy nine of the 150 samples were received from outpatient department while 71 were from inpatient department. Among 96 erythromycin resistant isolates of Staphylococcus aureus $78(81.2 \%)$ were found to be methicillin resistant while $39(72.2 \%)$ of the CONS were resistant to methicillin. Inducible clindamycin resistance was found in $39.3 \%$ of the isolates, constitutive resistance phenotype in $48 \%$ 
while $12.7 \%$ demonstrated MS phenotype. Constitutive resistant phenotype was the predominant phenotype in methicillin resistant isolates ( $S$. aureus and CONS both). MS phenotype was the predominant among MSSA while MRCNS isolates were equally distributed among iMLS and MS phenotypes $(26.7 \%)$ which predominated over cMLS (4.7\%) (Table 1).

MIC for erythromycin was found to be $\geq 240 \mu \mathrm{g} / \mathrm{ml}$ in all the resistant isolates. Among 59 iMLS isolates majority $(83 \%)$ were resistant to methicillin as well while most $(72.8 \%)$ of them were sensitive to vancomycin. $27.1 \%$ isolates showed intermediate sensitivity to vancomycin (MICs ranging between $4-8 \mu \mathrm{g} / \mathrm{ml}$ ), however these isolates were interpreted as sensitive on disk diffusion testing (zone size $>15 \mathrm{~mm}$ ). $16.7 \%$ of the cMLS and $57.9 \%$ of MS isolates were found to be oxacillin sensitive and $83 \%$ of iMLS and $83.3 \%$ of MS phenotype isolates were oxacillin resistant on MIC testing. $47.2 \%$ of cMLS and $73.6 \%$ of MS isolates had MIC $\leq 2 \mu \mathrm{g} / \mathrm{ml}$ (sensitive) for vancomycin and $52.7 \%$ of cMLS and $26.3 \%$ of MS isolates had MICs in intermediate ranege for vancomycin (Table 2).

About $18 \%$ of all the isolates had MICs ranging from $0.01-0.06 \mu \mathrm{g} / \mathrm{ml}$ and $11.3 \%$ had MICs between 0.06-0.1. $12.5 \%$ had MIC ranging from $4-8 \mu \mathrm{g} / \mathrm{ml}$ while $58 \%$ had MIC $>8 \mu \mathrm{g} / \mathrm{ml}$. Majority of the iMLS (47.4\%) and cMLS $(81.9 \%)$ isolates had MIC $>8 \mu \mathrm{g} / \mathrm{ml}$. All the isolates with MS phenotype had MIC between 0.01-0.06 $\mu \mathrm{g} / \mathrm{ml}$ (Table 3).

\section{DISCUSSION}

In recent times, clindamycin has become an excellent drug for some Staphylococcal infections, and as an alternative in penicillin-allergic patients. ${ }^{6}$ Also, clindamycin has good oral bioavailability making it a good option for outpatient therapy and changeover after intravenous antibiotics. ${ }^{9}$ However there has also been a considerable increase in resistance to clindamycin among clinical isolates including inducible resistance.

The differentiation of inducible $\mathrm{MLS}_{\mathrm{B}}\left(\mathrm{iMLS}_{\mathrm{B}}\right.$ phenotype) isolates from isolates with (MS phenotype) resistance is a critical issue because of the therapeutic implications of using clindamycin to treat a patient with an inducible clindamycin-resistant Staphylococcus aureus isolate.

Also from such isolates, spontaneous constitutively resistant mutants have arisen both in vitro testing and in vivo during clindamycin therapy. ${ }^{10}$ Moreover negative result for inducible clindamycin resistance confirms clindamycin susceptibility and provides a very good

\begin{tabular}{|c|c|c|c|c|c|}
\hline Phenotype & $\begin{array}{l}\text { MRSA } \\
(n=78)\end{array}$ & $\begin{array}{l}\text { MSSA } \\
(n=18)\end{array}$ & $\begin{array}{c}\text { MRCNS } \\
(n=39)\end{array}$ & $\begin{array}{c}\text { MSCNS } \\
(n=15)\end{array}$ & $\begin{array}{c}\text { Total } \\
(\mathrm{n}=150)(\%)\end{array}$ \\
\hline iMLS & 33 & 6 & 16 & 4 & $59(39.3)$ \\
\hline cMLS & 38 & 5 & 22 & 7 & $72(48)$ \\
\hline MS & 7 & 7 & 1 & 4 & 19 (12.7) \\
\hline
\end{tabular}

\begin{tabular}{|c|c|c|c|c|}
\hline Antibiotic & MIC $(\mu \mathrm{g} / \mathrm{ml})$ & iMLS ( $n=59)$ & $\operatorname{cMLS}(n=72)$ & MS (n=19) \\
\hline \multirow[t]{2}{*}{ Oxacillin } & $\leq 2$ & 10 & 12 & 11 \\
\hline & $\geq 4$ & 49 & 60 & 8 \\
\hline \multirow[t]{3}{*}{ Vancomycin } & $\leq 2$ & 43 & 34 & 14 \\
\hline & $4-8$ & 16 & 38 & 5 \\
\hline & $\geq 16$ & - & - & - \\
\hline
\end{tabular}

\begin{tabular}{|c|c|c|c|}
\hline MIC & iMLS (n=59) & cMLS $(n=72)$ & MS (n=19) \\
\hline $0.01-0.06$ & 8 & - & 19 \\
\hline $0.06-0.1$ & 13 & 4 & - \\
\hline $4-8$ & 10 & 9 & - \\
\hline$>8$ & 28 & 59 & - \\
\hline
\end{tabular}

therapeutic option. ${ }^{11}$ Hence it is of paramount importance to detect such resistance phenotypes in order to provide optimal treatment to the patients.

In our study from among 150 erythromycin resistant isolates, $39.3 \%$ had inducible clindamycin resistance. Further, this inducible resistance was higher in MRSA (42.3\%) isolates as compared to MSSA (33.3\%) and higher in MRCNS (41\%) compared to MSCNS (4.7\%). Similar pattern has been observed in earlier studies also. Gadepalli et al (2006) reported 30\% inducible clindamycin resistance in MRSA and $10 \%$ in MSSA. ${ }^{12}$ Also study conducted by Ajantha et al (2008) showed inducible inducible clindamycin resistance of $74 \%$ in MRSA and $45 \%$ in MSSA. ${ }^{13}$ But there are a few studies which have reported higher proportion of inducible resistance in MSSA (68\%) as compared to MRSA $(12.5 \%) .{ }^{14}$ Hence the true sensitivity to clindamycin may vary from hospital to hospital, geographic location, patient age, bacterial species, and bacterial susceptibility profile. ${ }^{15}, 16,17$

On disk diffusion testing, constitutive resistance (48\%) was found to be higher than inducible $(39.3 \%)$ and MS $(12.7 \%)$ phenotypes. Similar results were found in study by Fiebelkorn et a $\Gamma$ in 2003 in which out of 114 erythromycin-resistant Staphylococcus aureus isolates, 39 demonstrated constitutive resistance to clindamycin while 33 showed inducible resistance. We found $8.9 \%$ and 
$2.6 \%$ of MS phenotype in MRSA and MRCNS respectively. Though MS phenotype is not usually seen in methicillin resistant isolates but a study conducted by Gupta et $a l^{5}$ in 2009 demonstrated 16\% MS phenotype from MRSA. These differences highlight the variations and importance of inducible clindamycin resistance in different geographical settings.

MICs were determined for all isolates using E-test. Unlike disk diffusion test, $\mathrm{E}$ test did not differentiate among inducible and constitutive phenotypes. However we observed that all cMLS isolates with MICs for clindamycin in the sensitive range were lying between $0.06-0.1 \mu \mathrm{g} / \mathrm{ml}$ while among those with iMLS phenotype 8 isolates had MIC ranging from $0.01-0.06 \mu \mathrm{g} / \mathrm{ml}$ and 13 isolates had MIC between 0.06- $0.1 \mu \mathrm{g} / \mathrm{ml}$.

There were 21 isolates of staphylococci which had MICs in sensitive range but they revealed inducible resistance on disk diffusion testing. These patients would suffer treatment failure in case isolate is not specifically tested for induction. However, MIC determination helps to detect intermediate susceptibility to clindamycin which could not be detected in case only disk diffusion methods are employed. Also it is useful to correlate the MICs of antibiotics with resistance phenotypes. In our study we found $12.5 \%$ of cMLS and $16.9 \%$ of iMLS phenotype had MICs in intermediate range. In our study all the isolates with MS phenotype had MIC in sensitive range $(0.01-0.06 \mu \mathrm{g} / \mathrm{ml})$ indicating these isolates can be used for treatment. However, a study by Sireesha and Setty $^{1}$ in 2012 demonstrated MIC of clindamycin to be $>128 \mu \mathrm{g} / \mathrm{ml}$ in all the MS phenotypes which they attributed to heteroresistance or some other unknown mechanism. Moreover, there are also reports of successful use of clindamycin in treating patients with D-test-positive isolates. ${ }^{18,19}$ Studies have also revealed that it may be risky to use clindamycin when erythromycin testing shows a resistant or intermediate phenotype. ${ }^{14}$ Hence, MIC determination is an important tool to determine the use of antibiotics in patients where simple disk diffusion test characteristics could not differentiate sensitive from resistant isolates. Molecular markers for the erm gene are also available, but they are costly and inconvenient for everyday use. ${ }^{8,} 20$

Hence implementation of disc induction test provides an inexpensive, reproducible and reliable method during routine antimicrobial susceptibility testing to distinguish inducible from constitutive clindamycin resistance among isolates. E-test is also a simple laboratory method to determine MIC values and to identify isolates whose resistance pattern and hence clinical outcome cannot be ascertained by simple disk diffusion method.

\section{REFERENCES}

1. Sireesha $P$ and Setty $C R$. Detection of various types of resistance patterns and their correlation with minimal inhibitory concentrations against clindamycin among methicillin-resistant Staphylococcus aureus isolates. Indian jour of Med Micro 2012; 30: 165-169.

2. Ross JI, Farrell AM, Eady EA, Cove JH and Cunliffe WJ. Characterisation and molecular cloning of the novel macrolide-streptogramin B resistance determinant from Staphylococcus epidermidis. J Antimicrob Chemother 1989; 24:851-862.

3. Ross JI., Eady EA, Cove JH, Cunliffe WJ, Baumberg S, and Wootton JC. Inducible erythromycin resistance in Staphylococci is encoded by a member of the ATP-binding transport super-gene family. Mol Microbiol 1990; 4:1207-1214.

4. Roberts MC, Sutcliffe J, Courvalin $P$, Jensen LB, Rood J and Seppala H. Nomenclature for macrolide -lincosamide-streptogramin B resistance determinants. Antimicrob. Agents Chemother 1999; 43:2823-2830.

5. Gupta V, Datta P, Rani H and Chander J. Inducible clindamycin resistance in Staphylococcus aureus: A study from North India. JPGM 2009; 55: 176-179.

6. Drinkovic D, Fuller ER, Shore KP, Holland DJ and Ellis-Pegler R. Clindamycin treatment of Staphylococcus aureus expressing inducible clindamycin resistance. J Antimicrob Chemother 2001; 48:315-316.

7. Fiebelkorn KR, Crawford SA, McElmeel ML and Jorgensen JH. Practical disk diffusion method for detection of inducible clindamycin resistance in Staphylococcus aureus and coagulase negative staphylococci. J Clin Microbiol 2003; 41:740-744.

8. Clinical and laboratory standards institute. Performance standards for antimicrobial susceptibility testing; seventeenth informational supplement. Clinical Laboratory Standards Institute 2008; Vol. 2.

9. Laclercq R. Mechanisms of resistance to macrolides and lincosamides: Nature of resistance elements and their clinical implications. Clin Infect Dis 2002; 34: 482-492.

10. Yilmaz G, Aydin K, Iskender S, Caylan R and Koksal I. Detection and prevalence of inducible clindamycin resistance in staphylococci. J Med Microbiol 2007; 56:342-345.

11. Rodrigues Perez LR, Caierao J, Souza Antunes AL and Alves d'Azevedo P. Use of $D$ test method to detect inducible clindamycin resistance in coagulase negative staphylococci (CoNS). Braz J Infect Dis 2007; 11:186-188.

12. Gadepalli R, Dhawan B, Mohanty S, Kapil A, Das BK and Chaudhry R. Inducible clindamycin resistance in clinical isolates of Staphylococcus aureus. Indian J Med Res 2006; 123:571-573.

13. Ajantha GS, Kulkarni RD, Shetty J, Shubhada C and Jain P. Phenotypic detection of inducible clindamycin resistance amongst Staphylococcus aureus isolates by using lower limit of recommended inter-disk distance. Indian J Pathol Microbiol 2008; 51:376-378.

14. Levin TP, Suh B, Axelrod P, Truant AL and Fekete T. Potential clindamycin Resistance in clindamycin-susceptible, erythromycin-resistant Staphylococcus aureus: Report of a clinical failure. Antimicrob Agents Chemother 2005; 49:1222-1224.

15. Hamilton-Miller JMT and Shah S. Patterns of phenotypic resistance to the macrolide-lincosamide-ketolide-streptogramin group of antibiotics in staphylococci. J. Antimicrob Chemother 2000; 46:941-949.

16. Panagea S, Perry JD and Gould FK. Should clindamycin be used as treatment of patients with infections caused by erythromycin-resistant staphylococci? J. Antimicrob. Chemother 1999; 44:577-582. 
17. Siberry GK, Tekle T, Carroll K, and Dick J. Failure of clindamycin treatment of methicillin-resistant Staphylococcus aureus expressing inducible clindamycin resistance in vitro. Clin. Infect. Dis 2003; 37:1257-1260.

18. Frank Al, Marcinak JF, Mangat PD, Tjhio JT, Kelkar S, Schreckenberger JC, et al. Clindamycin treatment of methicillin-resistant Staphylococcus aureus infections in children. Pediatr Infect. Dis. J 2002; 21:530-534.

19. Martines-Aquilar G, Hammerman WA, Mason EO and
Kaplan SL. Clindamycin treatment of invasive infections caused by community-acquired, methicillin-resistant and methicillin-susceptible Staphylococcus aureus in children. Pediatr. Infect. Dis J 2003; 22:593-598.

20. Schmitz FJ, Petridou J, Fluit AC, Hadding U, Peters G and von Eiff C. Distribution of macrolide-resistant genes in Staphylococcus aureus blood-culture isolates from fifteen German university hospitals. Eur. J. Clin. Microbiol Infect. Dis 2000; 19:385-387.

\section{Authors Contribution:}

Dr. Fatima Khan: Conception and design of study. Dr. Sana Ali: Acquisition of data, article preparation. Dr. Asfia Sultan: Acquisition of data, data analysis, article preparation. Dr. Meher Rizvi: Critical revision. Abida Khatoon: Data analysis. Indu Shukla: Critical revision, Final approval. Haris M. Khaninal approval

Source of Support: Nil, Conflict of Interest: None declared. 